\title{
Productivity of Timber Processing in Ondo State, Nigeria
}

\author{
Adegboyega Eyitayo Oguntade ${ }^{1}$, Temitope Enitan Fatunmbi ${ }^{1} \&$ Joshua Adio Folayan ${ }^{1}$ \\ ${ }^{1}$ Department of Agricultural Economics and Extension, The Federal University of Technology, Akure \\ Correspondence: Temitope Enitan Fatunmbi, Department of Agricultural Economics and Extension, The Federal \\ University of Technology, Akure, Nigeria. Tel: 234-803-820-7726. E-mail: topefatunmbi@gmail.com
}

Received: May 15, 2012 Accepted: July 28, 2012 Online Published: August 5, 2012

doi:10.5539/sar.v2n1p1 URL: http://dx.doi.org/10.5539/sar.v2n1p1

\begin{abstract}
This study is aimed at evaluating the efficiency of timber processors in Ondo State, Nigeria, using Data Envelopment Analysis. Multi stage sampling technique was used to select two Local Government Areas with the highest number of sawmills, from each of which twenty saw millers were randomly selected, given a total of forty saw millers. Based on Constant Return to Scale Technical Efficiency, 35\% of the saw millers were technically efficient while on the basis of Variable Return to Scale TE, $60 \%$ of the saw millers were technically efficient. About $35 \%$ of the saw millers were scale efficient. The Data Envelopment Analysis output revealed that $35 \%$ of the sampled saw millers were both technically and scale efficient and were hence operating at the most productive scale size. About $65 \%$ of the saw millers were operating at sub-optimal condition. Excesses in input utilization were observed in respect of total fixed cost, costs of electricity, servicing of mill, timber from forest reserve and operation of truck; and remuneration of labour. The inefficient firms should be encouraged to emulate the operating practices of the most productive firms so as to improve their performance.
\end{abstract}

Keywords: wood, saw-millers, efficiency, scale

Abbreviations: Data Envelopment Analysis (DEA), Technical Efficiency (TE), Constant Return to Scale Technical Efficiency (CSRTE), Variable Return to Scale Technical Efficiency (VRSTE), Most Productive Scale Size (MPSS), Local Government Areas (LGAs)

\section{Introduction}

Wood is a fibrous rigid material of plant origin. It is broadly classified as hardwood and softwood. Hardwood is derived from angiosperm or broad-leaved trees such as Iroko (Meliaceae excelsa), Lagos Mahogany (Khaya ivorensis), Obeche (Triplochiton Scleroxylon), Opepe (Nauclea diderichii) and Danta (Nesogordonia papaverifera). Hardwood timbers are mainly used for structural application because of their high strength and durability. Softwood is obtained from coniferous trees, which have needle-like leaves. Softwood includes Scotts, larch, spruce and Douglas fir (Fuwape, 2000). Wood is a very important raw material. It is very useful in various works of life e.g. as a form of farming tool, as a source of building material, for fuel as well as weapons of hunting and warfare. Douglas (1995) noted that prior to the 19th century wood was the most important material used for construction and energy generation Timber is used in the construction of musical instruments, barns, fences, houses, bridges, etc.

Before now, Nigeria was rich in forest resources. In terms of relative contributions, the forest share of the real GDP, declined steadily from $4.2 \%$ in 1960 s, to about $1.87 \%$ in $1985,1.30 \%$ in 1995 and stood at about $1.2 \%$ in 1998 (CBN, 1999). The observed trend in the performance of the forestry sector in Nigeria requires urgent attention especially that the sector is crucial to the supply of forest products related industries in Nigeria such as sawmills, plywood mills, paper mills etc. All these wood related-industries contribute immensely to the economy in Nigeria (Adewumi, Adebayo, Abiodun, \& Caroline, 2004). Hence the wood supply status of Nigeria becomes very crucial. According to Liiro (1993), the wood supply status of Nigeria has deteriorated greatly as a result of ineffective control of forest resource exploitation. Coupled with this, is the inefficient conversion of wood resources in many sawmills. The future of wood-based industries in Nigeria remains bleak unless deliberate attempts are made to enhance the economic value of wood. Such attempts include the measurement of effectiveness and efficiency of resource use in the subsector.

Efficiency and effectiveness in timber processing is usually analyzed based on experience (Sundberg \& Silversides, 1987). Although this may suffice in some instances, however the complex situation associated with harvesting 
systems, processing techniques and business environment in timber processing today is such that a more accurate measure of efficiency should be employed. Accuracy in measurement is of enormous importance when innovations are obtained at a high cost. Understanding how these costs and other costs of processing timber affect technical efficiency will enhance the efficiency of individual wood processor (Alao \& Kuje, 2010).

According to Askin and Standbridg (1993) effectiveness is a process by which an appropriate task is accomplished while efficiency is a process by which a task is accomplished appropriately. On the other hand performance is doing the appropriate task efficiently. Therefore, performance is subject to efficiency, effectiveness, excellence, novelty, and success (Sink \& Tuttle, 1989).

This study had three main objectives, these are to:

1) estimate the outputs and costs of saw milling in Ondo State, Nigeria,

2) evaluate the technical efficiency of the saw millers, and

3 ) estimate the quantities of input used in excess of optimal level in the processing of timber.

\subsection{Technical Efficiency Measurement}

TE is stated as unit output produced divided by unit of inputs used in the course of production. Relative technical efficiency can be calculated by comparing the efficiency levels or scores of different firms in an industry against a universal yardstick. According to Ali and Seiford (1993), efficiency standard should be estimated because usually researchers work with experimental observations while the exact shape/location of the production frontier is not known. Farrell (1957) noted that a measure of inefficiency can be obtained by observing the difference between an observation and the production frontier line Technical efficiency measurement requires the capability to ensure a best performance.

Technical Efficiency can be measured using two major approaches. This division is subject to estimation of the production function. Parametric models, such as regression analysis and the stochastic frontier approach have been used in the wood industry, oil \& gas as well as food sub-sector (Carter \& Cubbage, 1995). Nonparametric models such as DEA have however experienced an increasing interest in research works today. Instances where non parametric approach has been used include; livestock/ dairy farming, (Fraser \& Cordina, 1999), and in the area of farm household efficiency measurements, (Wadud \& White, 2000), but have not been highly applied to forest harvesting and timber processing (Alao \& Kuje, 2010).

Linear programming approach is used to measure efficiency in Data Envelopment Analysis (DEA). This approach affords the data points to be enclosed which allows for connecting most efficient observations. The enclosure is known as the empirical production function since it is based on definite observations (Ali \& Seiford, 1993). Since DEA is a non-parametric method of calculating efficiency, there is no need to state guiding assumption regarding the statistical distribution of the variables of interest. Also, an assumption that all DMUs should have a common and identical production function is not required (Bernard, Cantner, \& Westermann, 1996).

\section{Materials and Methods}

\subsection{Study Area}

The study area was Ondo State, Nigeria. Data collection was done through a cross sectional survey of saw millers in the study area. Ondo State lies in the South-Western part of Nigeria. The state enjoys luxuriant vegetation with vast rainforest found in the south, while the northern fringe is mostly sub-savannah forest. The state has a tropical climate with moderate temperature all the year round. It experiences heavy rainfall between the months April and October of every year while the presence of dry wind is felt between the months of November and March. The mean rainfall pattern varies from $1000 \mathrm{~mm}$ to $1500 \mathrm{~mm}$ annually, with an average daily temperature of about $30^{\circ} \mathrm{C}$. Ondo State is characterized with decidous forests. Farming is the major occupation of the people of Ondo State. The major agricultural products are cocoa, kola, oil palm, cassava, maize and yam, while the main cash crop produced in the State is cocoa. The state is also blessed with tick forests (CPA Africa, 2010).

\subsection{Data Collection}

In order to obtain information on the variables of interest in this study, primary data were collected from 40 saw millers selected from two Local Government Areas (LGAs) (Akure South and Akure North) of Ondo State, Nigeria. In Akure South LGA, five major saw mails were identified while in Akure North LGA three major sawmills were identified. One saw mill in the study area consists of an average of eighteen saw millers. The multi-stage sampling technique was used in selecting the sampled saw millers. The first stage involved a purposive selection of two Local Government Areas. The second stage involved the selection of all the eight saw 
mills identified in both LGAs. In the third stage, five saw millers were randomly selected from each saw mill. Enumerators used a well structured questionnaire to collect information on socio-economic characteristics of the sampled saw millers, capital assets, production practices and costs, among others.

\subsection{Method of Analysis and Model Specification}

Descriptive statistics (measures of central tendency and dispersion) were used to analyze variables used in the efficiency analysis. In order to obtain efficiency values for each sampled saw miller DEA was used. Charnes and Cooper (1978) designed the Mathematical development of DEA and introduced Charnes-Cooper-Rhodes model-CCR model. CCR was later modified to achieve variable returns to scale conditions. The revision of CCR was to allow for convexity constraint. (Farrell, 1957; Banker, Charnes, \& Cooper, 1984; Coelli et al., 1998). The modified model is known as Banker-Charnes-Cooper model-BCC model. This model is given below as:

$$
\operatorname{Min}_{\theta}, \lambda \Theta
$$

Subject to:

$$
\begin{gathered}
-y i+Y \lambda \geq 0 \\
\Theta x i-X \lambda \geq 0 \\
\text { N1' } \lambda=1 \\
\lambda \geq 0
\end{gathered}
$$

Where; $\Theta$ is a scalar,

$\mathrm{N} 1^{\prime} \lambda=1$ is the convexity constraint,

$\mathrm{N} 1$ is $\mathrm{N} \times 1$ vector of constants,

yi is output vector of the $\mathrm{i}^{\text {th }} \mathrm{DMU}$,

$x i$ is input vector of the $i^{\text {th }} \mathrm{DMU}$,

$\mathrm{Y}$ is output matrix,

$\mathrm{X}$ is input matrix.

The efficiency score for the i-th firm is represented by $\Theta$. The linear programming problem specified above is therefore solved $\mathrm{N}$ times, each time for each DMU in the sample. An efficiency score of one (1) show that a firm is technically efficient (Farrell, 1957). According Based on Koopmans criteria (1951), a DMU is simply technically efficient if it operates on the frontier. He further explained that all associated slacks to the DMU should be zero for the firm to be technically efficient.

The DEA model has been modified into various versions, in one of this modifications, a multi-stage DEA model was developed to meet some criteria. The criteria is used to spot the nearest efficient points and to make the model independent of units of measurements. This led to the development of a multi-stage methodology and an analytical tool that creates a multi-stage model among other options. The analytical tool was later updated in 1997 in order to accommodate the latest development (Coeli, 1996; Coeli, 1997).

In DEA, Scale Efficiency (SE) score is simply an efficiency score acquired from the ratio of CRS to VRS. A SE score of one implies that a DMU is efficient given its scale of production level. If the value SE score is less than one $(<1)$, given the production scale of the firm, it implies that the firm is inefficient as far as thr scale of production is concerned. If the result of the DEA revealed that a firm is experiencing decreasing returns to scale, this implies that such a firm is at a super-optimal level. On the other hand, a firm that is experiencing increasing returns to scale is at a sub-optimal level (Gul et al., 2009).

Two outputs and seven inputs were used in this DEA model. The outputs were quantity of hardwood and soft wood processed $(\mathrm{kg})$. The inputs were: total fixed cost (i.e. depreciation of land, depreciation of ban saw, depreciation of truck, depreciation of generator and depreciation of machine), cost of electricity, cost of servicing mill, remuneration of labour, cost of timber from the forest, total cost of operating truck, cost of other input. All the inputs were cost items, so they were estimated in Naira ( $\$$ ). Data Envelopment Analysis Programmme (DEAP) version 2.1 was used to analyse the data. Firms' efficiency scores were obtained for CRS and VRS assumptions.

\section{Results and Discussion}

The descriptive statistics of key variables is presented in Table 1. The mean age of saw millers in the study area was about forty seven (47) years with standard deviation of 9.60. The result of the study also revealed that, an average saw miller in the study area has been in the saw milling business for at least 16 years. The mean 
household size was 8.95 . All but three of the respondents in the sampled area were male while $97.5 \%$ of them were married. Mean total fixed cost of processing timber into hard and soft wood in the study area was 495 596.86. The minimum and maximum fixed costs among the sampled saw millers were 154211 and $\$ 2935$ 000 respectively. The study revealed that the average cost of operating truck annually was 3928090.05 . This showed that cost of operating truck was the highest cost among all the cost items involved in the saw mill business. Cost of labour (that is wages and salaries) was 1275 320.10. This indicated that man power is another important element in the saw mill business.

Table 1 . Summary statistics of key variables

\begin{tabular}{lllll}
\hline Variables & Mean & Minimum & Maximum & Standard Deviation \\
\hline Age of the Respondent (Years) & 47.68 & 30 & 65 & 9.6 \\
Business Experience (Years) & 16.46 & 4 & 36 & 8.63 \\
Household Size & 9 & 3 & 21 & 5.14 \\
Total Fixed Cost (Naira) & 495596.86 & 154211 & 2935000 & 528238.61 \\
Cost of Electricity per Year (Naira) & 735900.00 & 168000 & 1638000 & 362296.65 \\
Annual Cost of Servicing Mill (Naira) & 453150.05 & 0 & 1800000 & 309039.09 \\
Annual Wages and Salaries (Naira) & 1275320.10 & 456000 & 6600000 & 1193948.70 \\
Cost of Timber Obtained from & & & & \\
Forest Reserve (Naira) & 144315.53 & 0 & 468000 & 159359.02 \\
Annual Cost of Operating Truck (Naira) & 3928090.05 & 0 & 15460000 & 2460796.71 \\
Annual Cost of Other Inputs (Naira) & 298608.00 & 140400 & 1736400 & 245134.88 \\
\hline
\end{tabular}

Source: Authors' computation.

Table 2 presents the TE scores for sampled saw millers in Ondo State. It revealed that for Constant Return to Scale Technical Efficiency (CSRTE), about 35\% of the sampled saw millers were technically efficient while the remaining saw millers were technically inefficient. Considering the Variable Return to Scale Technical Efficiency (VRSTE) orientation, $60 \%$ of the saw millers in the sampled area were technically efficient. On the scale efficiency, about $35 \%$ of the sampled saw mills were scale efficient while the remaining saw millers were scale inefficient. The DEA output revealed that $35 \%$ of the sampled saw millers were both technically (VRSTE) and scale efficient. This means that those saw millers that fell into this category were operating at the most productive scale size (MPSS). Inefficiency among some of the firms could be as a result inappropriate scale or inefficient combination of inputs.

Furthermore the table shows the characteristics of optimal, sub-optimal and super optimal saw mills. Majority $(65 \%)$ of the saw millers were operating under the sub-optimal condition. The mean scale efficiency of the sampled firms is relatively high (0.823). This implies that the level of efficiency in the sampled sawmill industry far above the average. 
Table 2. Efficiency scores by CRSTE and VRSTE and scale efficiency

\begin{tabular}{lccc}
\hline & CRSE (\%) & VRSE (\%) & SE (\%) \\
\hline $0.01-0.299$ & 5 & 0 & 5 \\
$0.3-0.399$ & 2.5 & 0 & 0 \\
$0.4-0,499$ & 2.5 & 0 & 2.5 \\
$0.5-0.599$ & 15 & 2.5 & 5 \\
$0.6-0.699$ & 7.5 & 7.5 & 5 \\
$0.7-0.799$ & 15 & 5 & 17.5 \\
$0.8-0.899$ & 10 & 7.5 & 17.5 \\
$0.9-0.999$ & 7.5 & 17.5 & 12.5 \\
1 & 35 & 60 & 35 \\
Total Percentage & 100 & 100 & 100 \\
Mean & 0.776 & 0.931 & 0.823 \\
Constant Return to Scale (Optimal) & $35.00 \%$ \\
Decreasing Return to Scale (Super optimal) & $0.00 \%$ \\
Increasing Return to Scale (Sub Optimal) & $65.00 \%$ \\
\hline
\end{tabular}

Source: Authors' computation.

Table 3. Efficient peers for inefficient firms

\begin{tabular}{cl}
\hline Inefficient Firms & Efficient Peers and Peer weights \\
\hline 6 & $4[0.013], 19[0.039], 16[0.047], 9[0.073], 37[0.074], 3[0.754]^{*}$ \\
7 & $4[0.001], 19[0.04], 16[0.025], 9[0.033], 37[0.088], 3[0.814]^{*}$ \\
8 & $2[0.133], 18[0.235], 34[0.632]^{*}$ \\
11 & $4[0], 34[0.01], 16[0.07], 9[0.052], 10[0.822]^{*}$ \\
12 & $10[0.158], 19[0.228], 9[0.273], 16[0.341]^{*}$ \\
15 & $10[0.009], 16[0.038], 9[0.121], 18[0.159], 37[0.225], 19[0.448]^{*}$ \\
17 & $19[0.004], 4[0.02], 9[0.182], 34[0.794]^{*}$ \\
20 & $4[0.04], 19[0.165], 32[0.231], 34[0.563]^{*}$ \\
21 & $4[0.001], 26[0.019], 10[0.098], 19[0.194], 18[0.687]^{*}$ \\
22 & $4[0.001], 18[0.066], 10[0.25], 19[0.341], 16[0.342]^{*}$ \\
23 & $4[0.01], 16[0.01], 19[0.176], 34[0.209], 9[0.225], 10[0.37]^{*}$ \\
24 & $19[0.156], 2[0.197], 16[0.224], 18[0.423]^{*}$ \\
27 & $4[0.009], 37[0.023], 3[0.064], 10[0.13], 9[0.139], 16[0.266], 19[0.369]^{*}$ \\
28 & $4[0.009], 9[0.09], 3[0.184], 19[0.315], 37[0.402]^{*}$ \\
29 & $16[0.082], 10[0.084], 19[0.094], 34[0.74]^{*}$ \\
33 & $4[0.008], 34[0.035], 10[0.119], 37[0.172], 19[0.282], 9[0.384]^{*}$ \\
35 & $2[0.011], 9[0.138], 34[0.177], 19[0.304], 37[0.37]^{*}$ \\
36 & $4[0.044], 37[0.052], 34[0.32], 9[0.584]^{*}$ \\
38 & $2[0.166], 26[0.184], 18[0.65]^{*}$ \\
39 & $26[0.07], 4[0.011], 30[0.037], 18[0.131], 2[0.325], 9[0.427]^{*}$ \\
40 & $9[0.048], 26[0.068], 19[0.072], 10[0.21], 18[0.602]^{*}$ \\
\hline
\end{tabular}

Source: Authors' computation; Figures in parenthesis are peer weights; *Most efficient peers. 
Table 3 indicates that for DMUs 6 and 7 to be efficient, they would have to emulate the operating practices of firm 3 which was an efficient peer operating at the most productive scale size. This is because firm 3 had the highest peer weight among all the peers in any of the cases. Hence, it was the most suitable firm whose operating practices should be studied by the inefficient firms. For firms 8, 17, 20 and 29 to be efficient, they would have to emulate the operating practices of firm 34 which was an efficient peer operating at the most productive scale size. Firm 10 would be copied by firms 11 and 23 in order for them to be efficient. For firms 12 and 22 to become efficient they must emulate the operations of firm 16. Firm 19 would be copied by firms 15 and 27 if they were to be efficient. For firms 21, 24, 38 and 40 to be efficient, they would have to emulate the operating practices of firm 18 which was an efficient peer operating at the most productive scale size. Firm 37 should be copied by firms 28 and 35 in order to become efficient. Finally for firms 33, 36 and 39 to be efficient, they could emulate the operational processes of firm 9.

The average amount of excess input used and the actual amount of input used in the production and processing of hard and soft wood were presented in Table 4. In technical efficiency analysis an excess of an input used is called slack. A firm can reduce its cost of production by subtracting the value of slack from the actual without experiencing reduction in total production. The table shows that there are opportunities for some of the firms to reduce their expenditures without reducing their outputs. Total fixed cost of producing hard and soft wood displayed a mean slack of $\$ 98930.28$ among 16 inefficient firms, these 16 inefficient firms can actually reduce their fixed expenses from $\$ 495596.86$ to $\$ 396666.58$ without experiencing reduction in output. From the analysis, 7 saw millers were experiencing slack in the cost of electricity, they were spending an excess of $\$ 48$ 007.32. Among the sampled saw millers in the study area, 14 inefficient firms spent an excess of $\$ 77261.54$ on cost of servicing mill while 12 firms spent an excess of $\$ 242391.80$ on remuneration of labour. Cost of timber from the Forest attracted an excess of $\$ 7933.81$ from 15 saw millers in the sampled area while 6 saw millers spent an excess of $\$ 187308.34$ on the cost of operating truck and 8 firms had a slack value of 39968.62 for cost of other input such as local and state government dues and tenement rates.

Table 4. Input slacks and number of firms using excess inputs

\begin{tabular}{|c|c|c|c|c|}
\hline Input & Number of firms & $\begin{array}{c}\text { Mean value of } \\
\text { Excess Cost }(\AA)^{\mathrm{a}}\end{array}$ & 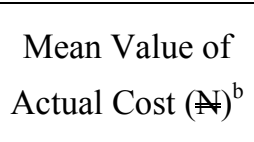 & $\begin{array}{c}\text { Ideal } \\
\text { Amount } \\
(\#)^{(\mathrm{b}-\mathrm{a})}\end{array}$ \\
\hline $\begin{array}{l}\text { Total Fixed Cost (Naira) } \\
\text { (N) }\end{array}$ & 16 & $98,930.28$ & $495,596.86$ & $396,666.58$ \\
\hline Cost of Electricity per Year (Naira) & 7 & $48,007.32$ & $735,900.00$ & $687,892.68$ \\
\hline Annual Cost of Servicing Mill (Naira) & 14 & $77,261.54$ & $453,150.05$ & $375,888.51$ \\
\hline Annual Wages and Salaries (Naira) & 12 & $242,391.80$ & $1,275,320.10$ & $1,032,928.30$ \\
\hline $\begin{array}{l}\text { Cost of Timber Obtained from } \\
\text { Forest Reserve (Naira) }\end{array}$ & 15 & $79,733.81$ & $144,315.53$ & $64,581.71$ \\
\hline Annual Cost of Operating Truck (Naira) & 6 & $187,308.34$ & $3,928,090.05$ & $3,740,781.71$ \\
\hline Annual Cost of Other Inputs (Naira) & 8 & $39,968.62$ & $298,608.00$ & $258,639.38$ \\
\hline
\end{tabular}

Source: Authors' computation.

\section{Conclusions and Recommendations}

This study assessed the operational costs of saw milling firms in Ondo State, Nigeria. It explained differences in TE of sampled sawmills. TE values of sampled saw millers were calculated using data from sampled saw millers in Ondo State.

The estimated mean TE of $93 \%$ is an indication that there is a $7 \%$ opportunity firms in the sampled saw mills to increase output of hard and soft wood while cost remains constant. Result of VRS indicated that, efficiency values ranged between 50 to $100 \%$ among the saw millers in the sampled area.

Excesses in input utilization were observed in respect of total fixed cost, cost of electricity, cost of servicing mill, remuneration of labour, cost of timber from the forest, total cost of operating truck, and cost of other inputs. All these excesses negatively affect the technical efficiency of the saw millers in the study area. The study revealed that inefficiency of firm was as a result of wrong combination of inputs which in turn unnecessarily increase cost. 
Thus, sawmills in the sampled area must be educated about the use and appropriate combination of these inputs in order to improve their effectiveness.

The findings of the study implies that saw millers should be exposed to new technologies that can enhance their operations and afford them the opportunity to reduce cost of processing. The inefficient firms should be encouraged to emulate the operating practices of the most productive firms so as to improve their performance.

\section{References}

Adewumi, O. I, Adebayo, M. S., Abiodun, O. O, \& Caroline, A. O. (2004). Cost and Returns Structure of Plank Business in Ijebu Division, Ogun State Nigeria. Ogun Journal of Agricultural Sciences, 3(1), 143-156.

Alao, J. S., \& Kuje, E. D. (2010). Determination of technical efficiency and production function for small scale furniture industry in lafia metropolis, Nasarawa State, Nigeria. J. Agric. Soc. Sci., 6, 64-66.

Ali, A. I., \& Seiford, L. M. (1993). The mathematical programming approach to efficiency analysis. In: Fried, H. O., C. A. K. Lovell, S. S. Schmidt, eds. The measurement of productive efficiency: techniques and applications. New York, NY: Oxford University Press.

Askin, R. G., \& Standbridge, C. R. (1993). Modeling and analysis of manufacturing systems, New York, NY: John Wiley and Sons, Inc.

Banker, R. D., Charnes, A., \& Cooper, W. W. (1984). Some models for estimating technical and scale inefficiencies in data envelopment analysis. Management Science, 30(9), 1078-1092. http://dx.doi.org/10.1287/mnsc.30.9.1078

Bernard, J., Cantner, U., \& Westermann, G. (1996). Technology leadership and variety: a Data Envelopment Analysis for the French Machinery Industry. Annals of Operations Research, 68, 361-377. http://dx.doi.org/10.1007/BF02207222

Carter, R. C., \& Cubbage, F. W. (1995). Stochastic Frontier Estimation and Sources of Technical Efficiency in Southern Timber Harvesting. Forest Science, 41(3), 576-593.

CBN. (1999). Central Bank of Nigeria Statistical Bulletin 10(2) CBN. Abuja.

CPA Africa. (2010). http://cpaafricaregion.org/taxonomy/term/47/0?page=3 Retrieved on 14/07/2012

Douglas, W.M. (1995): America's Forest: A history of resiliency and recovery: Forest Products Journal, 45(10) $18-28$.

Farrell, M. J. (1957). The measurement of productive efficiency. Journal of the Royal Statistical Society, 120(3), 253-281. http://dx.doi.org/10.2307/2343100

Fraser, I., \& Cordina, D. (1999). An application of data envelopment analysis to irrigated dairy farms in Northern

Fuwape, J. A. (2000). Wood Utilization: From Cradle to the Grave, 25th Inaugural Lecture of the Federal University of Technology, Akure, 5th December, 2000.

Koopmans, T. C. (1951). Analysis of Production as an Efficient Combination of Activities, in: T.C. Koopmans (ed). Activity Analysis of Production and Allocation, New Haven, Yale University Press. pp. 33-97.

Sink, D. S., \& Tuttle, T. C. (1989). Planning and measurement in your organization of the future. Institute of Industrial Engineers, Norcross, GA: Industrial Engineering and Management Press. p. 331.

Sundberg, U., \& Silversides, C. R. (1987). Operational Efficiency in Forestry. Kluwer Academic Publishers, Boston, MA. p. 219.

Wadud, A., \& White, B. (2000). Farm household efficiency in Bangladesh: A comparison of stochastic frontier and DEA methods. Applied Economics, 32-73. 